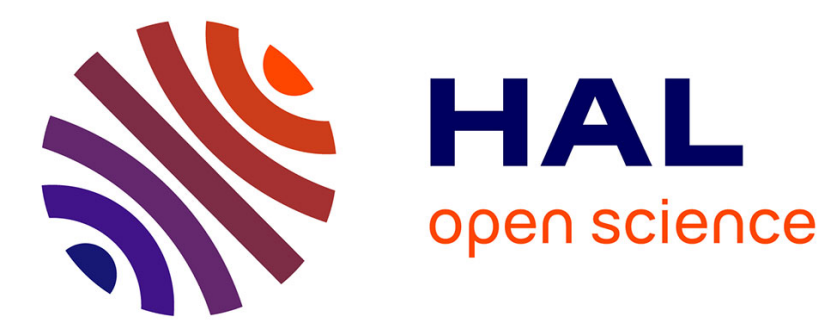

\title{
GENERAL FEATURES OF PHOTOPROTECTION BY ENERGY DISSIPATION IN PLANKTONIC DIATOMS (BACILLARIOPHYCEAE)
}

\author{
Johann Lavaud, Bernard Rousseau, Anne-Lise Etienne
}

\section{- To cite this version:}

Johann Lavaud, Bernard Rousseau, Anne-Lise Etienne. GENERAL FEATURES OF PHOTOPROTECTION BY ENERGY DISSIPATION IN PLANKTONIC DIATOMS (BACILLARIOPHYCEAE). Journal of Phycology, 2004, 40, pp.130-137. 10.1046/j.1529-8817.2004.03026.x . hal-01094173

\author{
HAL Id: hal-01094173 \\ https://hal.science/hal-01094173
}

Submitted on 11 Dec 2014

HAL is a multi-disciplinary open access archive for the deposit and dissemination of scientific research documents, whether they are published or not. The documents may come from teaching and research institutions in France or abroad, or from public or private research centers.
L'archive ouverte pluridisciplinaire HAL, est destinée au dépôt et à la diffusion de documents scientifiques de niveau recherche, publiés ou non, émanant des établissements d'enseignement et de recherche français ou étrangers, des laboratoires publics ou privés. 
Manuscript 03-026

GENERAL FEATURES OF PHOTOPROTECTION BY ENERGY DISSIPATION IN

PLANKTONIC DIATOMS (BACILLARIOPHYCEAE) ${ }^{1}$

Johann Lavaud ${ }^{2}$, Bernard Rousseau and Anne-Lise Etienne

Institution address: Laboratoire 'Organismes Photosynthétiques et Environnement', UMR

CNRS 8543, Ecole Normale Supérieure, 46 rue d’Ulm 75230 PARIS Cedex 05, France

${ }^{1}$ Received

${ }^{2}$ Author for correspondence: e-mail lavaud@biologie.ens.fr, phone +33 01443235 30, fax +330144323935

Running title: Photoprotection in diatoms 
Manuscript 03-026

\section{ABSTRACT}

Planktonic diatoms (Bacillariophyceae) have to cope with large fluctuations of light intensity and periodic exposure to high light. After a shift to high light, photoprotective dissipation of excess energy characterized by the non-photochemical quenching of fluorescence (NPQ) and the concomitant de-epoxidation of diadinoxanthin to diatoxanthin (DT) were measured in four different planktonic marine diatoms (Bacillariophyceae):

Skeletonema costatum (Greville) Cleve, Cylindrotheca fusiformis Reimann et Lewin, Thalassiosira weissflogii (Grunow) Fryxell et Hasle and Ditylum brightwellii (West) Grunow in comparison to the model organism Phaeodactylum tricornutum Böhlin. Upon a sudden increase of light intensity, de-epoxidation was rapid and de novo synthesis of DT also occurred. In all species, NPQ was linearly related to the amount of DT formed during high light. In this report, we focused on the role of DT in the dissipation of energy which takes place in the LHC. In $S$. costatum for the same amount of DT, less NPQ was formed than in P. tricornutum and as a consequence the photoprotection of PS II was less efficient. The general features of photoprotection by harmless dissipation of excess energy in planktonic diatoms described here partly explain why diatoms are well adapted to light intensity fluctuations.

Key Index Words: diadinoxanthin; diatoxanthin; non-photochemical fluorescence quenching; photoinhibition; photoprotection; planktonic diatoms; xanthophyll cycle

Abbreviations: Chl $a$, chlorophyll $a$; DD, diadinoxanthin; DT, diatoxanthin; LHC, lightharvesting complex; NPQ, non-photochemical fluorescence quenching; PS II, Photosystem II 
Manuscript 03-026

\section{INTRODUCTION}

Diatoms are ubiquitous primary producers accounting for approximately $40 \%$ of the primary carbon production in the oceans (Tréguer et al. 1995, Field et al. 1998). Planktonic diatoms (Bacillariophyceae) are the dominant group of phytoplankton. They have to cope with large fluctuations in light intensity and periodic exposures to high light (Harris 1986, Fogg 1991, Long et al. 1994). To survive a sudden increase in light intensity, photoprotective mechanisms are essential (Niyogi et al. 1998, Niyogi 2000). The non-radiative dissipation of excess energy is an important short-term process for the photoprotection of photosystem (PS) II against light-induced damage (Müller et al. 2001). Photoprotective dissipation is attributed to rapid modifications within the light-harvesting complex (LHC) of PS II leading to a nonphotochemical chlorophyll (Chl) $a$ fluorescence quenching (NPQ). NPQ is induced by the formation of a proton gradient across the thylakoid membrane $(\Delta \mathrm{pH})$ and is associated with the operation of a xanthophyll cycle, which converts epoxidized to de-epoxidized forms of xanthophylls. It has been largely documented in higher plants and green migroalgae (for reviews see Pfündel and Bilger 1994, Horton et al. 1996, Eskling et al. 1997, Gilmore 1997, Bassi and Caffarri 2000, Müller et al. 2001) but much less so in diatoms.

The photosynthetic apparatus of diatoms differs in many respects from that of green algae and higher plants. Thylakoid membranes are loosely appressed and organized in extended layers of three without grana stacking; PS I and PS II are randomly distributed (Pyszniak and Gibbs 1992). Diatoms have a specific set of pigments with Chl $c$, fucoxanthin and diadinoxanthin (DD) (which can be de-epoxidized to diatoxanthin, DT), in addition to the Chl $a$ and $\beta$-carotene found in all photosynthetic organisms (Brown 1988). The xanthophyll concentration relative to $\mathrm{Chl}$ can be two to four times more than in higher plant LHC (Wilhelm 1990, Passaquet et al. 1991). These pigments are bound to the LHC subunits that are composed of several highly homologous proteins encoded by a multigene family 
(fucoxanthin chlorophyll proteins, FCP, Bhaya and Grossman 1993). The exact organization of LHC subunits in diatoms, and especially the location of DD and its de-epoxidation within these complexes, is currently being studied (Lavaud et al. 2003). No obvious orthologs of some of the important components of LHC of higher plant PS II (e. g. the minor antennae CP 26, CP 29 and CP 22 (PsbS protein)) have been found in Phaeodactylum tricornutum Böhlin or within the genome sequence of Thalassiosira pseudonana Hustedt (Hasle and Heimdal) (Müller et al. 2001, C. Bowler, personal com.).

Studies of the photoprotective dissipation of excess energy in diatoms have mostly been performed using P. tricornutum as a model organism (Ting and Owens 1993, Arsalane et al. 1994, Olaizola et al. 1994, Casper-Lindley and Bjorkman 1998, Goss et al. 1999, Mewes and Richter 2002). This choice results in part from the fact that this species is easy to grow and maintain in artificial conditions in dense cultures. In P. tricornutum, we have previously shown that NPQ indeed has a photoprotective effect for the PS II reaction centers under an excess of light (Lavaud et al. 2002a). NPQ depends on the size of the DD pool and can reach much larger values than in higher plants (Lavaud et al. 2002a, Li et al. 2002c). NPQ and DT were linearly related and if DT is not present, NPQ cannot be formed (Lavaud et al. 2002a, Lavaud et al. 2002b). Nevertheless, the ecological relevance of $P$. tricornutum is weak compared to other diatom species. In order to define some general features of photoprotection in diatoms, we compared the effects of high light illumination on four species of planktonic marine diatoms: Cylindrotheca fusiformis Reimann et Lewin, Ditylum brightwellii (West) Grunow and two ecologically relevant species Skeletonema costatum (Greville) Cleve, Thalassiosira weissflogii (Grunow) Fryxell et Hasle. The photoprotective dissipation of excess energy (kinetics of DD de-epoxidation and of NPQ formation) was characterized in each species as well as in P. tricornutum as a control. For the species with the smallest and the 
Manuscript 03-026

largest NPQ (S. costatum and P. tricornutum, respectively), the kinetics of PS II photoinhibition were compared.

\section{MATERIALS AND METHODS}

\section{Cultures}

Phaeodactylum tricornutum Böhlin (Laboratoire Arago algal collection, Banyuls-surMer, France), Skeletonema costatum UTEX-LB2308 (Greville) Cleve (University of Texas Collection (UTEX), Austin), Cylindrotheca fusiformis CCMP343 Reimann et Lewin (ProvasoliGuillard National Center for Culture of marine Phytoplankton (CCMP), West Boothbay Harbor, Maine), Thalassiosira weissflogii CCMP1051 (Grunow) Fryxell et Hasle, and Ditylum brightwellii CCMP359 (West) Grunow cells were grown photoautotrophically in sterile natural seawater F/2 medium (Guillard and Ryther 1962). Non-axenic cultures of $300 \mathrm{~mL}$ were incubated at $18^{\circ} \mathrm{C}$ in airlifts continuously flushed with sterile air. They were illuminated at a light intensity of $40 \mu \mathrm{mol}$ photons. $\mathrm{m}^{-2} . \mathrm{s}^{-1}$ with white fluorescent tubes (Claude, Blanc Industrie, France) with a $16 \mathrm{~h}$ light/8 h dark photoperiod. Cells were harvested during the exponential phase of growth, centrifuged at $3000 \mathrm{~g}$ for $10 \mathrm{~min}$ and resuspended in their culture medium to a final concentration of $10 \mu \mathrm{g} \mathrm{Chl} a \cdot \mathrm{mL}^{-1}$. The concentrated suspension was then continuously stirred at $18^{\circ} \mathrm{C}$ under low light before use.

Pigment content.

Pigment analyses were performed by HPLC as previously described (Arsalane et al. 1994, Lavaud et al. 2003). Cells collected from the Clark electrode adapted to the PAMfluorometer (see below) were deposited on a filter and frozen in liquid nitrogen. Pigments were extracted with a methanol:acetone (70:30, v/v) solution. Published extinction coefficients for Chl 
Manuscript 03-026

(Berkaloff et al. 1990) and for diadinoxanthin (DD) and diatoxanthin (DT) (Johansen et al. 1974) were used. Cell counts were performed with a Thoma hematocymeter, using the public domain NIH Image program (US National Institute of Health).

\section{Chl fluorescence yield and non-photochemical fluorescence quenching (NPQ).}

Chl fluorescence yield was monitored with a modified PAM-101 fluorometer (Walz, Effeltrich, Germany) as described previously (Ritz et al. 1999). A Clark electrode was adapted to the PAM light guides in order to record simultaneously oxygen and fluorescence. Fluorescence was excited by a very weak (non-actinic) modulated $650 \mathrm{~nm}$ light. After 20 min dark-adaptation, continuous actinic light of adjustable intensity was applied. $600 \mathrm{~ms}$ pulses of white light (4000 $\mu \mathrm{mol}$ photons. $\mathrm{m}^{-2} . \mathrm{s}^{-1}$ ) were admitted by an electronic shutter (Uniblitz, Vincent, USA, opening time $2 \mathrm{~ms}$ ) placed in front of a KL-1500 quartz iodine lamp continuously switched on in order to monitor NPQ evolution. The average fluorescence (acquisition time $33 \mu \mathrm{s}$ ) measured during the last $400 \mathrm{~ms}$ of the pulse was taken as $\mathrm{F}_{\mathrm{m}}$ or $\mathrm{F}_{\mathrm{m}}$. Data were recorded with a computer through a 12 bit analogue-digital interface and the system was driven by home-made software (Arsalane et al. 1993). For each experiment, $2 \mathrm{~mL}$ of cell suspension were used. Sodium bicarbonate was added at a concentration of $4 \mathrm{mM}$ from a freshly prepared $0.2 \mathrm{M}$ stock solution in distilled water to prevent any limitation of the photosynthetic rate by carbon supply.

Standard fluorescence nomenclature was used (van Kooten and Snel 1990). $F_{o}$ and $F_{m}$ are defined as the minimum PS II fluorescence yield of dark-adapted cells and the maximum PS II fluorescence yield reached in such cells during a saturating pulse of white light, respectively. The quantum yield of excitation trapping by PS II is the ratio $F_{v} / F_{m}$ where $F_{v}$ is the variable part of the fluorescence emission and is equal to $\mathrm{F}_{\mathrm{m}}-\mathrm{F}_{\mathrm{o}}$. Non-photochemical fluorescence quenching (NPQ or $\mathrm{SV}_{\mathrm{m}}$ ) is quantified by the 'Stern-Volmer' expression $\mathrm{F}_{\mathrm{m}} / \mathrm{F}_{\mathrm{m}}$-1, where $\mathrm{F}_{\mathrm{m}}$ ' is the maximum PS II fluorescence yield of light-adapted cells (Krause and Weis 1991). NPQ 
Manuscript 03-026

quantified by the 'Stern-Volmer' expression is proportional to the concentration of the deepoxidized xanthophyll zeaxanthin or DT (Gilmore and Yamamoto 1991, Lavaud et al. 2002a). Non-photochemical quenching also occurs on the minimal fluorescence level $F_{o}$ and is also proportional to the concentration of DT (Lavaud et al. 2002a). It is expressed as $\mathrm{SV}_{\mathrm{o}}=$ $\mathrm{F}_{\mathrm{o}} / \mathrm{F}_{\mathrm{o}}{ }^{\prime}-1$ where $\mathrm{F}_{\mathrm{o}}{ }^{\prime}$ is the PS II fluorescence yield of light-adapted cells. It is always smaller than NPQ (or $\mathrm{SV}_{\mathrm{m}}$ ) (Lavaud et al. 2002a). While NPQ is frequently used because it is the most easy to determine, $F_{o}{ }^{\prime}$ is also very useful to determine the quantum yield of photochemistry in the presence and absence of DT with the following relationship: $\Phi_{\mathrm{Q}[\mathrm{DT}=0]} / \Phi_{\mathrm{Q}[\mathrm{DT}]}=\mathrm{F}_{\mathrm{o}} / \mathrm{F}_{\mathrm{o}}{ }^{\prime}($ Lavaud et al. 2002a).

$\mathrm{O}_{2}$ yield per flash

The relative $\mathrm{O}_{2}$ yield produced per flash during a sequence of single-turnover saturating flashes at a frequency of $2 \mathrm{~Hz}$ was measured at $18^{\circ} \mathrm{C}$ with a rate electrode as described by Lemasson and Etienne 1975. Short $(5 \mu \mathrm{s})$ saturating flashes were produced by a Strobotac (General Radio Co., Concord, MA). For the control sequences, cells were first darkadapted for $20 \mathrm{~min}$ and then deposited on the electrode. Both control and illuminated samples taken from the PAM-fluorimeter were allowed to settle on the electrode for 7 min in darkness before measurement. The steady-state $\mathrm{O}_{2}$ yield per flash $\left(\mathrm{Y}_{\mathrm{SS}}\right)$ was attained for the last flashes of a sequence of twenty flashes when the classical four-step oscillations due to the S-states cycle (Kok et al. 1970) were fully damped. $Y_{S S}$ was used to evaluate the relative number of oxygen producing PS II reaction centers (see Lavaud et al. 2002a).

\section{RESULTS}

Characteristics of the five species of diatoms. 
Under the same growth conditions, growth rate, cell size and Chl $a$ content per cell of the five species were different but, as can be seen in Table 1, the relative pigment concentrations were rather similar, with a large amount of fucoxanthin, and 5 to 10 times less $\mathrm{DD}$ and $\mathrm{Chl} c$. The amount of DD ranged between 7 and $9 \mathrm{~mol} / 100 \mathrm{~mol} \mathrm{Chl} \mathrm{a}$ and at the light intensities used for culturing ( $40 \mu \mathrm{mol}$ photons. $\left.\mathrm{m}^{-2} . \mathrm{s}^{-1}\right)$ no DT was present. $\beta$-carotene, known to be bound to the core complexes of both photosystems, was also present in similar quantities. The quantum yield of PS II estimated by the ratio $F_{v} / F_{m}$ was similar for all species.

Characteristics of the xanthophyll cycle.

After the light shift, de-epoxidation of DD to DT occurred rapidly and after a few minutes (at most), DD reached a minimal value (Fig. 1). The rate of de-epoxidation can be estimated by fitting the decrease of $\mathrm{DD}$ with an exponential $\left(\left[\mathrm{DD}_{\mathrm{t}}=\left(\mathrm{DD}_{\text {initial }}-\mathrm{DD}_{\text {minimal }}\right) \mathrm{x} \mathrm{e}^{-}\right.\right.$ $\left.{ }^{k t}\right]$ ). The values found for the rate constant are shown in Table 2. They vary between 2.2 and $1.2 \mathrm{~min}^{-1}$, the fastest de-epoxidation being in P. tricornutum. The maximum de-epoxidation observed was around $50 \%$. It was smaller for T. weissflogii and D. brightwellii (Table 2). If the duration of illumination exceeded $15 \mathrm{~min}$ at the highest intensity used (2000 $\mu \mathrm{mol}$ photons. $\mathrm{m}^{-2} \cdot \mathrm{s}^{-1}$ ), which is equivalent to full sunlight (Long et al. 1994), then a slow synthesis of DT independent of DD de-epoxidation (de novo DT synthesis, Olaizola et al. 1994) could be observed. The rate of de novo DT synthesis (estimated from the slope of the slow DT increase independent of DD de-epoxidation) varied by a factor of two between all species (Table 2). The three parameters shown in Table 2 were all light dependent, as illustrated for $P$. tricornutum using a $1 \mathrm{~h}$ illumination duration and two different light intensities of 450 and $2000 \mu \mathrm{mol}$ photons. $\mathrm{m}^{-2} \cdot \mathrm{s}^{-1}$. The light dependency observed for all species. The de-epoxidation rate, degree of de-epoxidation and rate of de novo DT synthesis were larger at higher light intensities (Table 3). 
Manuscript 03-026

\section{Correlation between DT accumulation and $N P Q$.}

We have previously shown that in $P$. tricornutum grown under low light intensities, NPQ and DT were linearly related (Lavaud et al. 2002a, Lavaud et al. 2002b). In the five strains, the values of DT and NPQ were concomitantly determined in two different ways: i) by varying the illumination time from 0.5 to $60 \mathrm{~min}$ at $2000 \mu \mathrm{mol}$ photons.m ${ }^{-2} . \mathrm{s}^{-1}$ (Fig. 1 and 2) and ii) by varying the light intensity from 50 to $2000 \mu \mathrm{mol}$ photons $. \mathrm{m}^{-2} . \mathrm{s}^{-1}$ for a fixed illumination time of $5 \mathrm{~min}$ (not shown). These data were used to define the correlation between NPQ and DT (Fig. 3A and B). The regression coefficient of the linear relationship was close to one for all species except for $S$. costatum, in which it was lower (0.5). In $S$. costatum, for the same amount of DT, two times less NPQ was formed. In T. weissflogii, for values above $3 \mathrm{~mol}$ DT/100 mol Chl $a$, the regression coefficient between NPQ and DT was smaller (Fig. 3B).

Comparison of PS II photoinhibition and recovery kinetics for P. tricornutum and S. costatum.

During an illumination at $2000 \mu \mathrm{mol}$ photons. $\mathrm{m}^{-2} \cdot \mathrm{s}^{-1}$, the variation in the relative concentration of active PSII reaction centers was determined, as a function of the duration of illumination up to $45 \mathrm{~min}$, by measuring the steady-state oxygen yield per flash for the strains with the largest (P. tricornutum) and the lowest (S. costatum) NPQ. Under excess light illumination photoinactivation of PS II reaction centers was faster in S. costatum than in $P$. tricornutum, as shown in Figure 4. In vivo, photoinhibition occurs in at least two steps: 1) inactivation of PS II reaction centers activity which can be reversed in the dark, 2) inhibition irreversible in the dark (Kirilovsky et al. 1990). To estimate the irreversible part of dark photoinhibition, the number of active PS II reaction centers was measured after $30 \mathrm{~min}$ of 
Manuscript 03-026

dark relaxation for the different illumination times at $2000 \mu \mathrm{mol}$ photons. $\mathrm{m}^{-2} \cdot \mathrm{s}^{-1}$ (Fig. 4). In both species, a partial relaxation was observed but the difference between $P$. tricornutum and S. costatum remained: photoinhibition was more pronounced in S. costatum than in $P$. tricornutum.

\section{DISCUSSION}

DD de-epoxidation characteristics and two different pathways for DT synthesis.

The rapid kinetics of de-epoxidation of DD into DT which takes place in all the strains may be due to the fact that a weak proton gradient is sufficient to activate the DD deepoxidase (Jakob et al. 2001). DD de-epoxidation thus begins rapidly after the onset of high light and the rate is light intensity-dependent. Part of DD molecules may be constitutive within the LHC (Lohr and Wilhelm 2001) inaccessible to the de-epoxidase, and thus nonconvertible, as observed for violaxanthin in higher plants (Ruban et al. 1999). This might be the main reason for the incomplete de-epoxidation of $\mathrm{DD}(50-55 \%$ in vivo). The pool of the convertible population of DD can vary in size and is most likely weakly bound at the periphery of the pigment-protein complexes (Lavaud et al. 2003) or even in the lipid membrane of the thylakoid, as suggested for violaxanthin in higher plants (Eskling et al. 1997 and citations within).

For all species examined, exposure to excess light beyond the first 15-30 min leads to further DT accumulation not resulting from DD de-epoxidation. Such DT synthesis has already been reported and denoted de novo DT synthesis (Olaizola et al. 1994, Olaizola and Yamamoto 1994). It corresponds to a direct conversion of violaxanthin into DT without a DD intermediate (Lohr and Wilhelm 2001) because it is insensitive to dithiothreitol, an inhibitor of DD de-epoxidation (Olaizola et al. 1994). The rate of de novo DT synthesis varies between species and with light intensity and duration. 
Manuscript 03-026

Correlation between the light induced DT and NPQ.

With the accumulation of DT, a concomitant formation of NPQ is observed. The direct linear correlation between NPQ and DT concentration, previously found in P. tricornutum (Lavaud et al. 2002a, Lavaud et al. 2002b), exists also in the other species studied. All regressions show a slope of 1 , except $S$. costatum for which it is 0.5 . For T. weissflogii, the slope changes for DT values above $3 \mathrm{~mol} / 100 \mathrm{~mol} \mathrm{Chl} a$. According to Figure 1, it could mostly correspond to de novo synthesized DT molecules but this may not be true at other light intensities. We tentatively propose that the smaller slope observed with $T$. weissflogii for high values of DT is the result of a combination between a slope 1 and a horizontal line, indicating that a fraction of the DT molecules does not bind to the NPQ locus in the LHC because it becomes saturated. In $S$. costatum, the slope is smaller from the start, possibly indicating that the amount of DT involved in NPQ is a smaller fraction of the total pool. It has been shown in higher plants that an increase in the pool of violaxanthin did not influence the amplitude of NPQ (Davidson et al. 2002). Also in S. costatum the amount of the specific component(s) of LHC involved in NPQ could be lower than in other species. Li et al. 2002c recently demonstrated that, other parameters being unchanged, especially the degree of deepoxidation, NPQ was doubled by increasing the expression of the PsbS protein. The molecules of DT which are not directly involved in NPQ could nevertheless play a different photoprotective role by preventing thylakoid membrane lipids from photo-oxidation during prolonged exposure to high light as shown for its analogue zeaxanthin in higher plants (Havaux and Niyogi 1999). In this case, de-epoxidized xanthophylls are located in the lipid matrix of thylakoid membrane (Eskling et al. 1997 and citations within). 
Manuscript 03-026

Protection against PS II photoinhibition by $N P Q$.

NPQ has been shown to account for the efficiency of photoprotection of PS II against photoinactivation in P. tricornutum cultures with different NPQ capabilities (Arsalane et al. 1994, Lavaud et al. 2002a). Such a correlation had not been tested for different diatoms with different NPQ characteristics. We have shown previously in P. tricornutum that energy dissipation involving DT equally decreases the quantum yield of oxygen evolution and the quantum yield of fluorescence emission. We have now shown in this report that for the same light treatment and for the same DD/DT pool size, there is two times less NPQ (or $\mathrm{SV}_{\mathrm{m}}$ ) formed in $S$. costatum than in P. tricornutum. As excepted, $\mathrm{SV}_{\mathrm{o}}$ is also smaller in $S$. costatum than in P. tricornutum for the same DT concentration (data not shown) and therefore the decrease of the quantum yield of photochemistry is smaller for S. costatum than for $P$. tricornutum. As a consequence, kinetics of PS II photoinhibition are faster in S. costatum than in P. tricornutum and the irreversible part of photoinhibition is larger in S. costatum than in $P$. tricornutum.

In summary, in the present report, we have shown that what has been found in the model organism $P$. tricornutum is also valid for other marine planktonic diatoms. They react rapidly to a sudden increase in light intensity protecting their PS II reaction centers (the main target of photoinhibition) by dissipation of excess energy in the antenna complex of PS II. DT plays a crucial role in this mechanism. A second role for DT which could be prevention of lipid peroxidation needs to be verified. Even though the amplitude and regulation of energy dissipation are species dependent, the following general features can be drawn: (1) a fast DD de-epoxidation and concomitant formation of NPQ (within seconds); (2) a direct linear relationship between DT accumulation and NPQ development; (3) a de novo synthesis of DT that accounts for supplementary photoprotection under prolonged illumination; and (4) all 
Manuscript 03-026

parameters (especially those concerning the xanthophyll cycle) are regulated by the light regime. Because recent studies in higher plants show clearly that PsbS plays a major role for energy dissipation and photoprotection ( $\mathrm{Li}$ et al. 2002a, Li et al. 2002b, Aspinall-O'Dea et al. 2002, Li et al. 2002c), it is intriguing that an ortholog has not been found in diatoms. The possibility that another type of protein plays a similar role has not yet been explored.

\section{ACKNOWLEDGMENTS}

We thank G. Vétion from the Laboratoire Arago, Banyuls-sur-Mer, France for kindly providing us the Skeletonema costatum strain. We thank Dr C. Bowler and Dr. J. Houmard for critical reading and improvement of the manuscript. J. L. thanks the French Ministry of National Education, Research and Technology for financial support.

\section{REFERENCES}

Arsalane, W., Paresys, G., Duval, J.-C., Wilhelm, C., Conrad, R. \& Büchel, C. 1993. A new fluorometric device to measure the in vivo chlorophyll $a$ fluorescence yield in microalgae and its use as a herbicide monitor. Eur. J. Phycol. 28:247-52.

Arsalane, W., Rousseau, B. \& Duval, J.-C. 1994. Influence of the pool size of the xanthophyll cycle on the effects of light stress in a diatom: Competition between photoprotection and photoinhibition. Photochem. Photobiol. 60:237-43.

Aspinall-O'Dea, M., Wentworth, M., Pascal, A., Robert, B., Ruban, A. \& Horton, P. 2002. In vitro reconstitution of the activated zeaxanthin state associated with energy dissipation in plants. Proc. Natl. Acad. Sci. USA 99:16331-35.

Bassi, R. \& Caffarri, S. 2000. LHC proteins and the regulation of photosynthetic light harvesting function by xanthophylls. Photosynth. Res. 64:243-56. 
Berkaloff, C., Caron, L. \& Rousseau, B. 1990. Subunit organization of PSI particles from brown algae and diatoms: polypeptide and pigments analysis. Photosynth. res. 23:181-93. Bhaya, D. \& Grossman, A. R. 1993. Characterization of gene clusters encoding the fucoxanthin chlorophyll proteins of the diatom Phaeodactylum tricornutum. Nucleic Acids Res. 21:4458-66.

Brown, J. S. 1988. Photosynthetic pigment organization in diatoms (Bacillariophyceae). J. Phycol. 24:96-102.

Casper-Lindley, C. \& Bjorkman, O. 1998. Fluorescence quenching in four unicellular algae with different light-harvesting and xanthophyll-cycle pigments. Photosynth. Res. 56:277-89. Davidson, P. A., Hunter, C. N. \& Horton, P. 2002. Overexpression of $\beta$-carotene hydroxylase enhances stress tolerance in Arabidopsis. Nature 418:203-06.

Eskling, M., Arvidsson, P. O. \& Akerlund, H. E. 1997. The xanthophyll cycle, its regulation and components. Physiol. Plantarum 100:806-16.

Field, C. B., Behrenfeld, M. J., Randerson, J. T. \& Falkowski, P. 1998. Primary production of the biosphere: integrating terrestrial and oceanic components. Science 281:237-40.

Fogg, G. E. 1991. The phytoplanktonic ways of life. New Phytol. 118:191-232.

Gilmore, A. M. 1997. Mechanistics aspects of xanthophyll cycle-dependent photoprotection in higher plant chloroplasts and leaves. Physiol. Plantarum 99:197-209.

Gilmore, A. M. \& Yamamoto, H. Y. 1991. Zeaxanthin formation and energy-dependent fluorescence quenching in pea chloroplasts under artificially mediated linear and cyclic electron transport. Plant Physiol. 96:635-43.

Goss, R., Mewes, H. \& Wilhelm, C. 1999. Stimulation of the diadinoxanthin cycle by UV-B radiation in the diatom Phaeodactylum tricornutum. Photosynth. Res. 59:73-80.

Guillard, R. R. R. \& Ryther, J. H. 1962. Studies of marin planktonic diatoms. 1. C. nana (Hustedt) and D. confervacea (Cleve). Gran. Can. J. Microbiol. 8:229-38. 
Manuscript 03-026

Harris, G. P. 1986. Phytoplankton Ecology: Structure, Function, and Fluctuation. Chapman \& Hall, London, UK.

Havaux, M. \& Niyogi, K. K. 1999. The violaxanthin cycle protects plants from photooxidative damage by more than one mechanism. Proc. Natl. Acad. Sci. USA 96:8762-67. Horton, P., Ruban, A. V. \& Walters, R. G. 1996. Regulation of light harvesting in green plants. Annu. Rev. Plant Physiol. Plant Mol. Biol. 47:655-84.

Jakob, T., Goss, R. \& Wilhelm, C. 2001. Unusual pH-dependence of diadinoxanthin deepoxidase activation causes chlororespiratory induced accumulation of diatoxanthin in the diatom Phaeodactylum tricornutum. J. Plant Physiol. 158:383-90.

Johansen, J. E., Wa, S., Liaaen-Jensen, S. \& Haxo, F. T. 1974. Carotenoids of the Dinophyceae. Phytochem. 13:2261-71.

Kirilovsky, D. L., Vernotte, C. \& Etienne, A. L. 1990. Protection from photoinhibition by low temperature in Synechocystis 6714 and in Chlamydomonas reinhardtii: detection of an intermediary state. Biochemistry USA 29:8100-06.

Kok, B., Forbush, B. \& Mc Gloin, M. 1970. Cooperation of charges in photosynthetic O2 evolution-I. A linear four step mechanism. Photochem. Photobiol. 11:457-75.

Krause, G. H. \& Weis, E. 1991. Chlorophyll fluorescence and photosynthesis: the basics. Ann. Rev. Plant Physiol. Plant Mol. Biol. 42:313-49.

Lavaud, J., Rousseau, B. \& Etienne, A.-L. 2002b. In diatoms, a transthylakoidal proton gradient alone is not sufficient for non-photochemical fluorescence quenching. FEBS Letters 523:163-66.

Lavaud, J., Rousseau, B. \& Etienne, A.-L. 2003. Enrichment of the light-harvesting complex in diadinoxanthin and implications for the nonphotochemical fluorescence quenching in diatoms. Biochemistry USA 42:5802-08. 
Manuscript 03-026

Lavaud, J., Rousseau, B., van Gorkom, H. \& Etienne, A.-L. 2002a. Influence of the diadinoxanthin pool size on photoprotection in the marine planktonic diatom Phaeodactylum tricornutum. Plant Physiol. 129:1398-06.

Lemasson, C. \& Etienne, A.-L. 1975. Photo-inactivation of system II centers by carbonyl cyanide m-chlorophenylhydrazone in Chlorella pyrenoidosa. Biochim. Biophys. Acta 408:135-42.

Li, X.-P., Gilmore, A. M. \& Niyogi, K. K. 2002b. Molecular and global time-resolved analysis of a psbS gene dosage effect on $\mathrm{pH}$ - and xanthophyll cycle-dependent nonphotochemical quenching in photosystem II. J. Biol. Chem. 277:33590-97. Li, X.-P., Müller-Moulé, P., Gilmore, A. M. \& Niyogi, K. K. 2002c. PsbS-dependent enhancement of feddback de-excitation protects photosystem II fom photoinhibition. Proc. Natl. Acad. Sci. USA 99:15222-27.

Li, X.-P., Phippard, A., Pasari, J. \& Niyogi, K. K. 2002a. Structure-function analysis of photosystem II subunit S (PsbS) in vivo. Funct. Plant Biol. 29:1131-39.

Lohr, M. \& Wilhelm, C. 2001. Xanthophyll synthesis in diatoms: quantification of putative intermediates and comparison of pigment conversion kinetics with rate constants derived from a model. Planta 212:382-91.

Long, S., Humphries, S. \& Falkowski, P. 1994. Photoinhibition of photosynthesis in nature. Ann. Rev. Plant Physiol. Plant Mol. Biol. 45:633-62.

Mewes, H. \& Richter, M. 2002. Supplementary ultraviolet-B radiation induces a rapid reversal of the diadinoxanthin cycle in the strong light-exposed diatom Phaeodactylum tricornutum. Plant Physiol. 130:1527-35.

Müller, P., Li, X.-P. \& Niyogi, K. K. 2001. Non-photochemical quenching. A response to excess light energy. Plant Physiol. 125:1558-66.

Niyogi, K. K. 2000. Safety valves for photosynthesis. Curr. Opin. Plant Biol. 3:455-60. 
Niyogi, K. K., Grossman, A. R. \& Bjorkman, O. 1998. Arabidopsis mutants define a central role for the xanthophyll cycle in the regulation of photosynthetic energy conversion. Plant Cell 10:1121-34.

Olaizola, M., Laroche, J., Kolber, Z. \& Falkowski, P. G. 1994. Non-photochemical fluorescence quenching and the diadinoxanthin cycle in a marine diatom. Photosynth. Res. 41:357-70.

Olaizola, M. \& Yamamoto, H. Y. 1994. Short-term response of the diadinoxanthin cycle and fluorescence yield to high irradiance in Chaetoceros muelleri (Bacillariophyceae). J. Phycol. 30:606-12.

Passaquet, C., Thomas, J. C., Caron, L., Hauswirth, N., Puel, F. \& Berkaloff, C. 1991. Lightharvesting complexes of brown algae - Biochemical characterization and immunological relationships. FEBS Letters 280:21-26.

Pfündel, E. E. \& Bilger, W. 1994. Regulation and possible function of the violaxanthin cycle. Photosynth. Res. 42:89-109.

Pyszniak, A. M. \& Gibbs, S. P. 1992. Immunocytochemical localisation of photosystem I and the fucoxanthin-chlorophyll a/c light-harvesting complex in the diatom Phaeodactylum tricornutum. Protoplasma 166:208-17.

Ritz, M., Neverov, K. V.\& Etienne, A.-L. 1999. $\Delta$ pH-dependent fluorescence quenching and its photoprotective role in the unicellular red alga Rhodella violacea. Photosynthetica 37:26780.

Ruban, A. V., Lee, P. J., Wentworth, M., Young, A. J. \& Horton, P. 1999. Determination of the stoichiometry and strength of binding of xanthophylls to the photosystem II light harvesting complexes. J. Biol. Chem. 274:10458-65.

Ting, C. S. \& Owens, T. G. 1993. Photochemical and non-photochemical fluorescence quenching processes in the diatom Pheaodactylum tricornutum. Plant Physiol. 101:1323-30. 
Manuscript 03-026

Tréguer, P., Nelson, D. M., van Bennekom, A. J., DeMaster, D. J., Leynaert, A. \& Quéginer, B. 1995. The silica balance in the world ocean: a reestimate. Science 268:375-79.

van Kooten, O. \& Snel, J. F. H. 1990. The use of chlorophyll fluorescence nomenclature in plant stress physiology. Photosynth. Res. 25:147-50.

Wilhelm, C. 1990. The biochemistry and physiology of light-harvesting processes in chlorophyll $b$ - and chlorophyll $c$-containing algae. Plant Physiol. Biochem. 28:293-306. 
Manuscript 03-026

\section{FIGURE LEGENDS}

Figure 1. DD de-epoxidation and DT accumulation kinetics for the five species of diatoms. DD (open symbols, dotted line), DT (solid symbols) and DD+DT (open symbols, dashed line) as a function of illumination duration at $2000 \mu \mathrm{mol}$ photons. $\mathrm{m}^{-2} \cdot \mathrm{s}^{-1}$ : (A) P. tricornutum (circles), (B) S. costatum (triangles), (C) C. fusiformis (squares), (D) T. weissflogii (diamonds), (E) D. brightwellii (inverted triangles). Data ( $\pm \mathrm{SD})$ are the average of two to four measurements.

Figure 2. Non-photochemical quenching development during 60 min illumination at $2000 \mu \mathrm{mol}$ photons. $\mathrm{m}^{-2} . \mathrm{s}^{-1}$; (insert) enlargement of the first $5 \mathrm{~min}$. P. tricornutum (circles), S. costatum (triangles), C. fusiformis (squares), T. weissflogii (diamonds), D. brightwellii (inverted triangles). Data $( \pm \mathrm{SD})$ are the average of three to six measurements.

Figure 3. Correlation of NPQ and DT concentration. (A) P. tricornutum (circles), C. fusiformis (squares) and D. brightwellii (inverted triangles); and for (B) P. tricornutum (circles), S. costatum (triangles) and T. weissflogii (diamonds). NPQ and DT were formed by varying the illumination time from 0.5 to $60 \mathrm{~min}$ at $2000 \mu \mathrm{mol}$ photons. $\mathrm{m}^{-2} \cdot \mathrm{s}^{-1}$ (data from Fig. 1 and 2) and by varying the light intensity from 50 to $2000 \mu \mathrm{mol}$ photons. $\mathrm{m}^{-2} \cdot \mathrm{s}^{-1}$ for a fixed illumination duration of 5 min (not shown). Linear regressions: $\mathrm{NPQ}(P t)=0.95$ [DT], $\mathrm{NPQ}(C f)=0.96[\mathrm{DT}], \mathrm{NPQ}(D b)=1.04[\mathrm{DT}] ; \mathrm{NPQ}(S c)=0.49[\mathrm{DT}], \mathrm{NPQ}(T w)=0.99$ $[\mathrm{DT} \leq 3], \mathrm{NPQ}(T w)=0.34[\mathrm{DT}>3]$, with $0.91<\mathrm{R}^{2}<0.99$.

Figure 4. Loss of active PS II reaction centers during illumination at $2000 \mu$ mol photons.m ${ }^{2} \cdot \mathrm{s}^{-1}$ (solid symblos) in P. tricornutum (circles) and S. costatum (triangles), for different duration of illumination up to $45 \mathrm{~min}$, immediately after the cessation of light and after 30 
Manuscript 03-026

min dark relaxation (open symbols). $30 \mathrm{~min}$ is the time sufficient for the relaxation of the dark reversible step of photoinhibition as monitored with the chlorophyll fluorescence emission. The number of active PS II reaction centers was estimated by the steady-state $\mathrm{O}_{2}$ yield per flash. It was normalized to the activity $(100 \%)$ measured in dark-adapted cells. Data $( \pm$ SD) are the average of three to four measurements. 
Manuscript 03-026

Table 1. Quantum yield of PS II $\left(\mathrm{F}_{\mathrm{v}} / \mathrm{F}_{\mathrm{m}}\right)$ and pigment content of the five planktonic marine diatoms examined.

\begin{tabular}{ccccccc}
\hline \hline Species & $\mathrm{F}_{\mathrm{v}} / \mathrm{F}_{\mathrm{m}}{ }^{\mathrm{a}}$ & Fucoxanthin & $\mathrm{Chl} c$ & $\mathrm{DD}$ & $\mathrm{DT}$ & $\beta$-carotene \\
& $( \pm 0.03)$ & & $\left(\mathrm{mol} .100 \mathrm{~mol} \mathrm{Chl} a^{-1}\right)$ & \\
\hline P. tricornutum & 0.77 & $67.1 \pm 1.3$ & $13.1 \pm 0.6$ & $9.2 \pm 1.7$ & 0 & $7.4 \pm 0.3$ \\
S. costatum & 0.77 & $73.3 \pm 1.8$ & $15.3 \pm 1.2$ & $8.3 \pm 2.1$ & 0 & $6.4 \pm 0.5$ \\
C. fusiformis & 0.79 & $71.4 \pm 1.9$ & $17.5 \pm 0.9$ & $6.6 \pm 0.6$ & 0 & $5.7 \pm 0.4$ \\
T. weissflogii & 0.79 & $53.6 \pm 1.6$ & $11.1 \pm 0.5$ & $9.4 \pm 0.9$ & 0 & $8.3 \pm 1.5$ \\
D. brightwellii & 0.82 & $81.3 \pm 1.8$ & $22.7 \pm 0.4$ & $7.5 \pm 0.4$ & 0 & $6.9 \pm 0.5$ \\
& & & & & & \\
\hline
\end{tabular}

$\left({ }^{a}\right) F_{v} / F_{m}\left(F_{v}=F_{m}-F_{o}\right)$ is the quantum yield of PS II. Data $( \pm$ SD) are the average of two to four measurements.

Lavaud, Rousseau and Etienne 
Manuscript 03-026

Table 2: Characteristics of the DD de-epoxidation and DT de novo synthesis measured under $2000 \mu \mathrm{mol}$ photons. $\mathrm{m}^{-2} \cdot \mathrm{s}^{-1}$

\begin{tabular}{|c|c|c|c|}
\hline Species & $\begin{array}{c}k^{\mathrm{a}} \\
\left(\min ^{-1}\right)\end{array}$ & $\begin{array}{c}\text { Degree of de-epoxidation }^{b} \\
(\%)\end{array}$ & $\begin{array}{l}\text { Rate of de novo DT synthesis } \\
\quad\left(\mathrm{mmol} . \mathrm{mol} \mathrm{Chl} a^{-1} \cdot \mathrm{min}^{-1}\right)\end{array}$ \\
\hline P. tricornutum & $2.2 \pm 0.6$ & $50 \pm 1$ & $0.54 \pm 0.05$ \\
\hline S. costatum & $1.7 \pm 0.3$ & $50 \pm 4$ & $0.59 \pm 0.09$ \\
\hline C. fusiformis & $1.2 \pm 0.1$ & $47 \pm 5$ & $0.26 \pm 0.08$ \\
\hline T. weissflogii & $1.4 \pm 0.1$ & $33 \pm 6$ & $0.36 \pm 0.04$ \\
\hline D. brightwellii & $1.2 \pm 0.1$ & $40 \pm 1$ & $0.24 \pm 0.05$ \\
\hline
\end{tabular}

$\left({ }^{a}\right) k$ is the rate constant of DD de-epoxidation (see equation in the Results section). ${ }^{b}$ ) The degree of DD de-epoxidation is [DT/(DD+DT)x 100] measured before DT de novo synthesis starts (30 min for P. tricornutum, S. costatum and C. fusiformis, $15 \mathrm{~min}$ for T. weissflogii and D. brightwelii). Data ( $\pm \mathrm{SD})$ are the average of two to three measurements.

Lavaud, Rousseau and Etienne 
Manuscript 03-026

Table 3. Effect of light intensity on the DD de-epoxidation and DT de novo synthesis in P. tricornutum cells.

\begin{tabular}{|c|c|c|c|}
\hline $\begin{array}{c}\text { Light intensity } \\
\left(\mu \mathrm{mol} \text { photons. } \mathrm{m}^{-2} \cdot \mathrm{s}^{-1}\right)\end{array}$ & $\begin{array}{c}k^{\mathrm{a}} \\
\left(\min ^{-1}\right)\end{array}$ & $\begin{array}{c}\text { Degree of de-epoxidation }^{b} \\
(\%)\end{array}$ & $\begin{array}{l}\text { Rate of de novo DT synthesis } \\
\quad\left(\mathrm{mmol} \cdot \mathrm{mol} \mathrm{Chl} a^{-1} \cdot \mathrm{min}^{-1}\right)\end{array}$ \\
\hline $450^{c}$ & 1.4 & 32 & 0.27 \\
\hline 2000 & 2.8 & 51 & 0.50 \\
\hline
\end{tabular}

$\left({ }^{\mathrm{a}}\right) k$ is the rate constant of DD de-epoxidation (see equation in the Results section). $\left(^{b}\right)$ The degree of DD de-epoxidation is [DT/(DD+DT)x 100] measured before DT de novo synthesis starts (from $30 \mathrm{~min}$ for the two light intensities). $\left(^{c}\right) 450 \mu \mathrm{mol}$ photons. $\mathrm{m}^{-2} \cdot \mathrm{s}^{-1}$ is just saturating for the oxygen emission (as measured with a Clark electrode) while $2000 \mu$ mol photons. $\mathrm{m}^{-2} \cdot \mathrm{s}^{-}$ ${ }^{1}$ corresponds to full sunlight (well above saturation).

Lavaud, Rousseau and Etienne 
Figure 1-Lavaud, Rousseau and Etienne

A
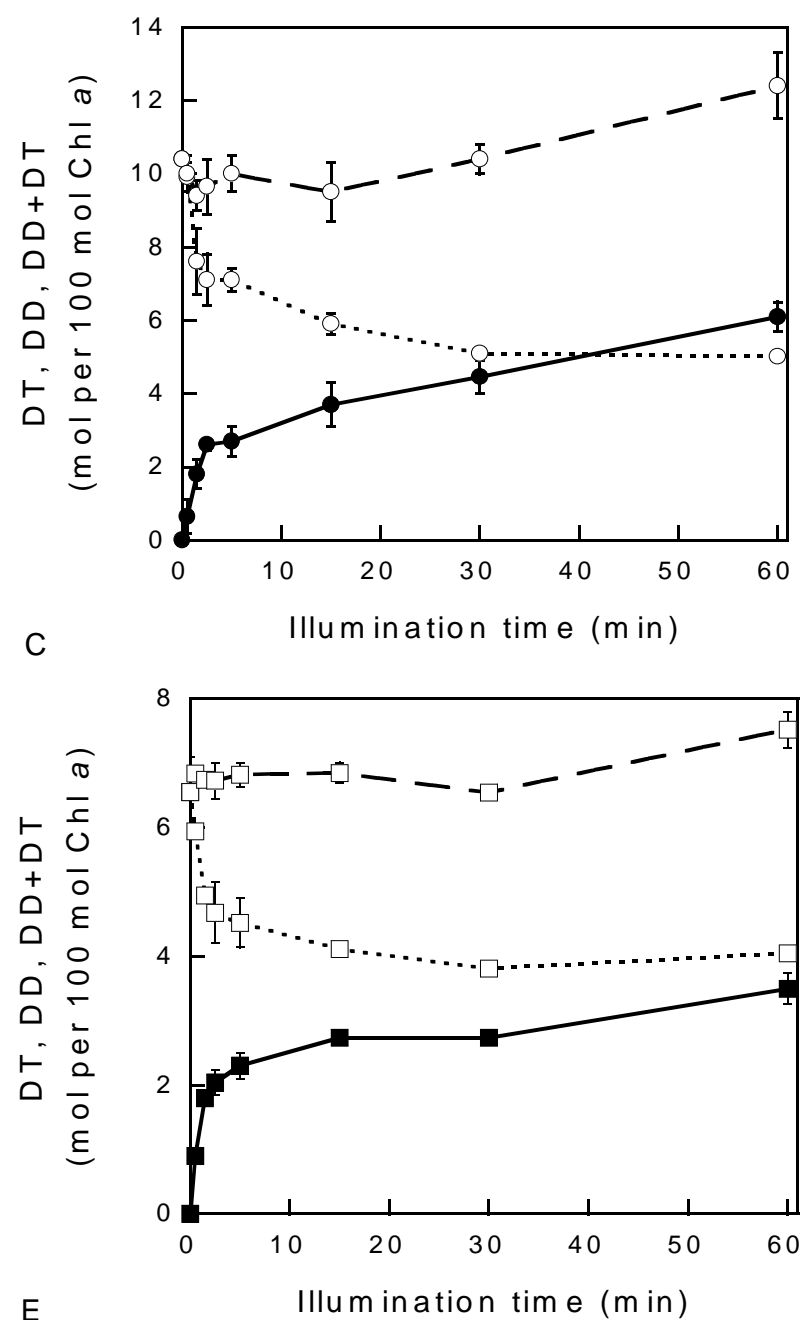

E

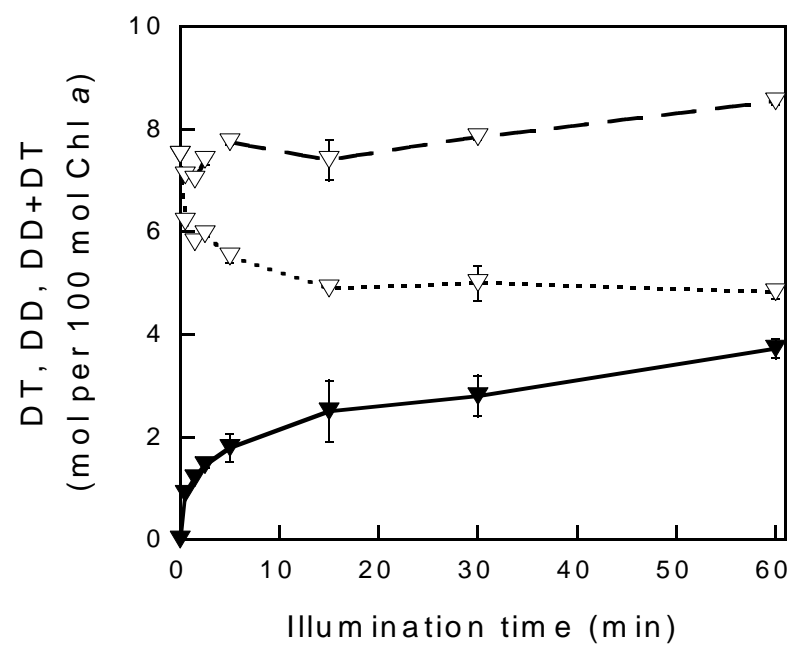

B

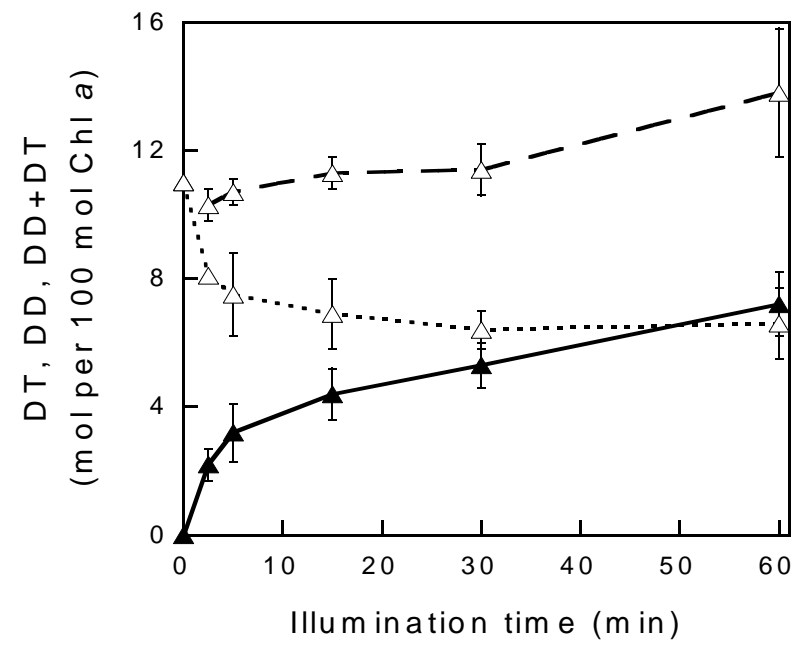

D

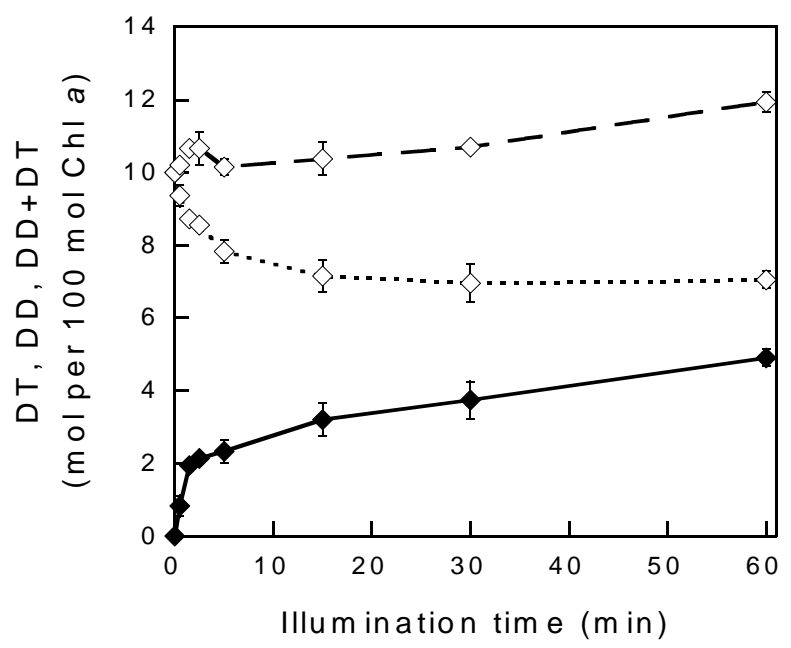


Manuscript 03-026

Figure 2-Lavaud, Rousseau and Etienne

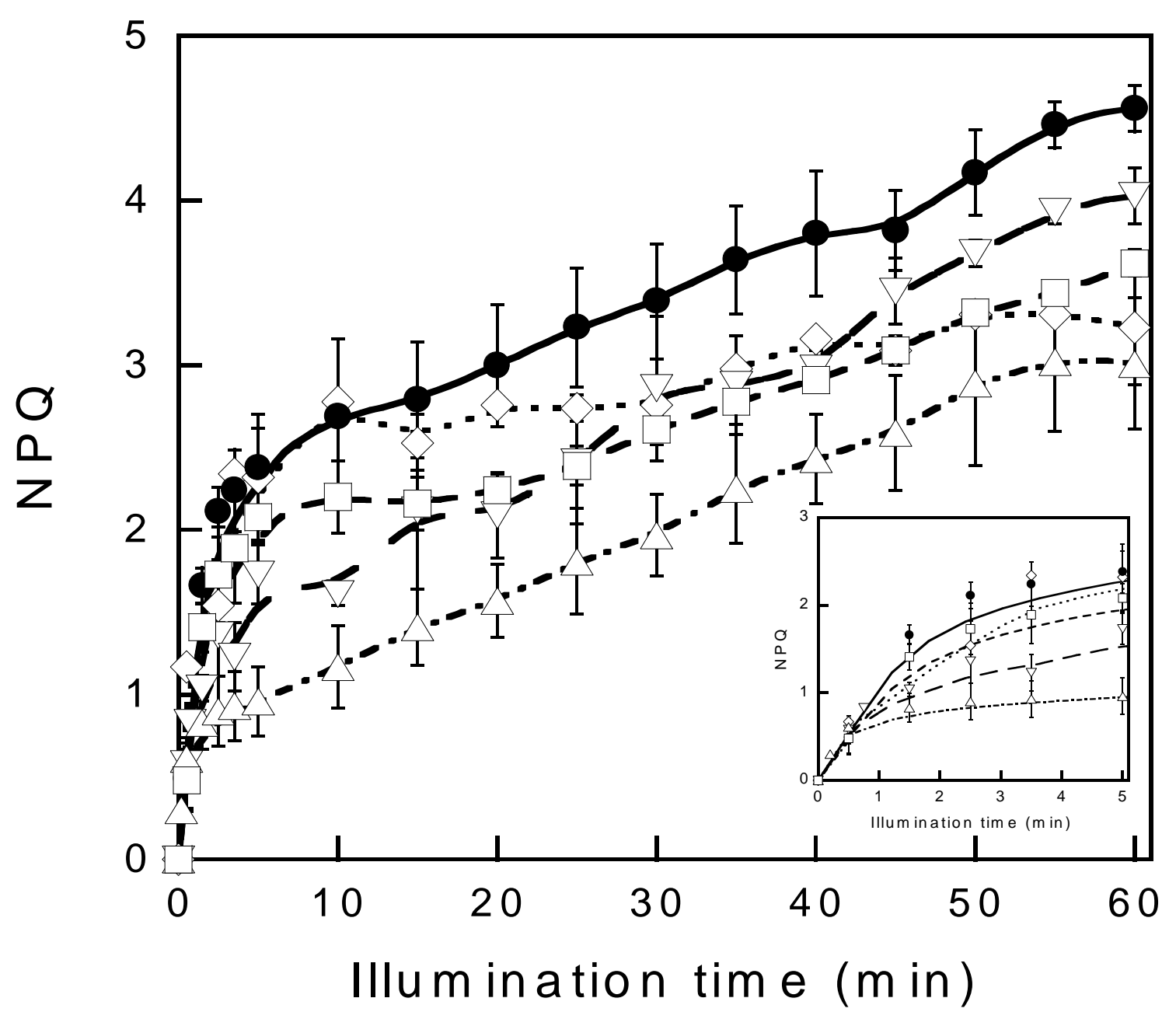


Manuscript 03-026

Figure 3-Lavaud, Rousseau and Etienne

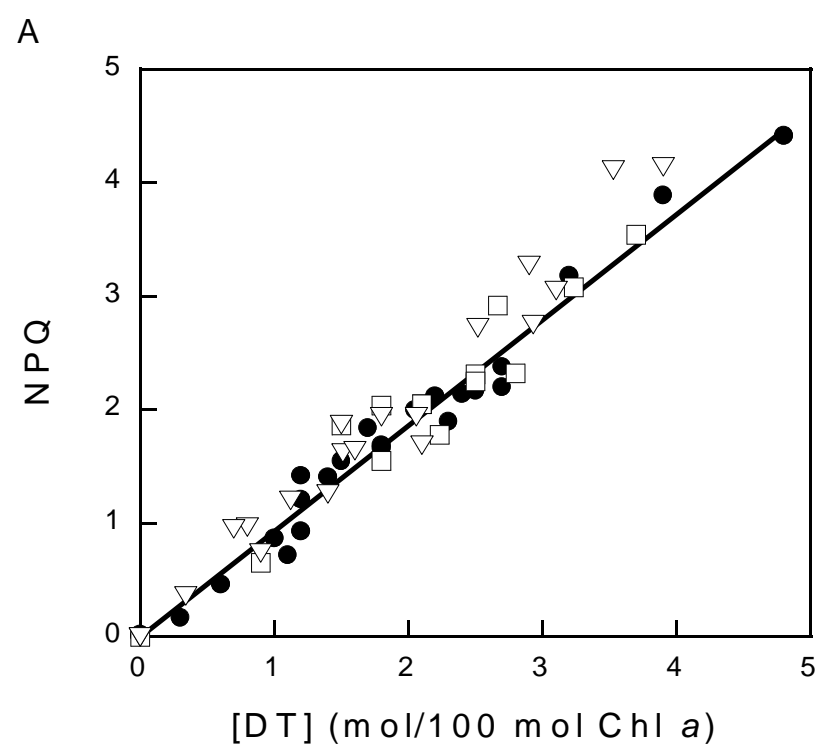

B

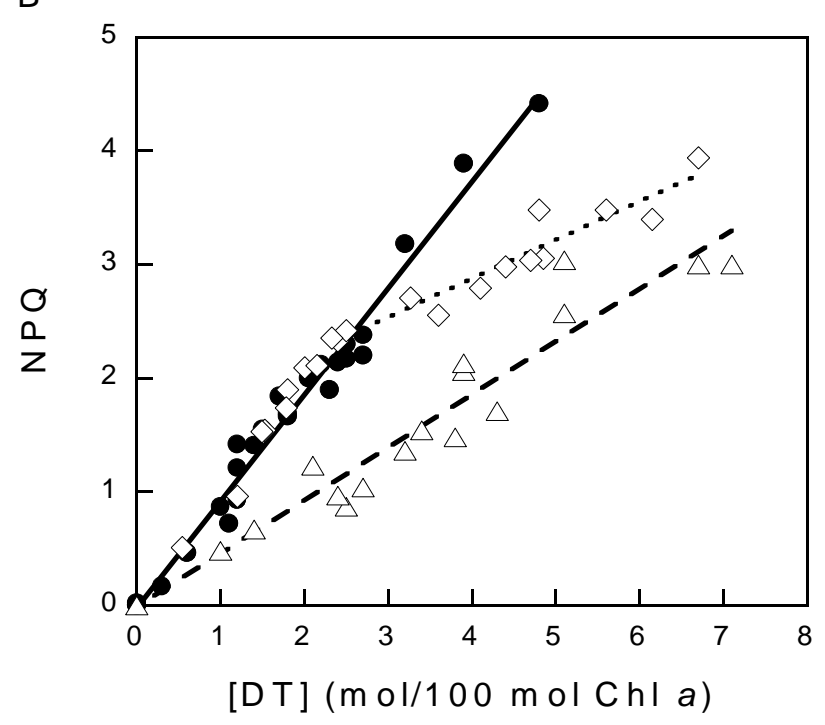


Manuscript 03-026

Figure 4-Lavaud, Rousseau and Etienne

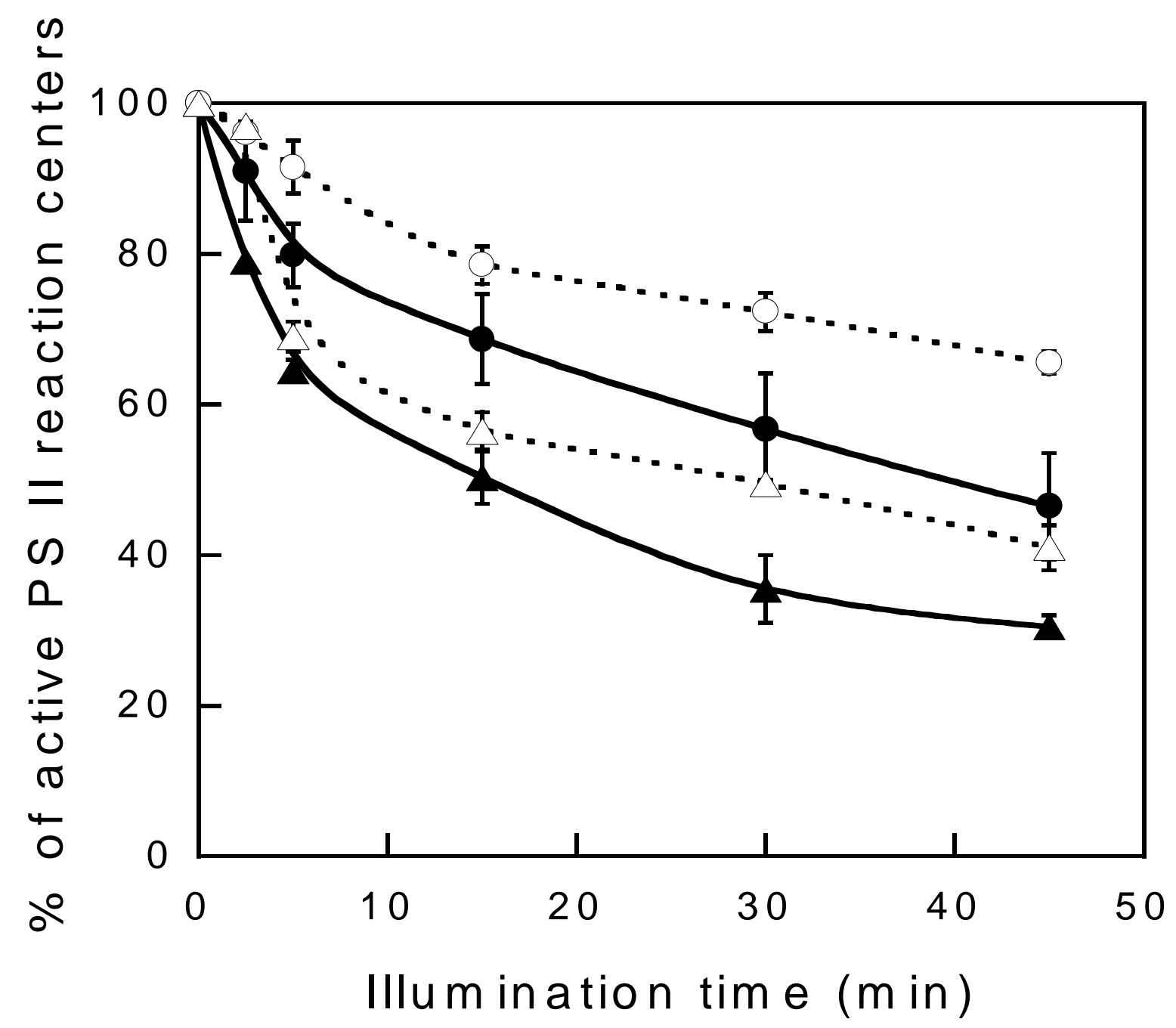

